\title{
AVALIAÇÃO DA SUSTENTABILIDADE NA BIBLIOTECA CENTRAL SANTA MÔNICA DA UNIVERSIDADE FEDERAL DE UBERLÂNDIA/MG
}

ASSESSMENT OF SUSTAINABILITY IN THE SANTA MONICA CENTRAL LIBRARY OF THE FEDERAL UNIVERSITY OF UBERLÂNDIA/MG

EVALUACIÓN DE LA SOSTENIBILIDAD EN LA BIBLIOTECA CENTRAL SANTA MÓNICA DE LA UNIVERSIDAD FEDERAL DE UBERLÂNDIA/MG

${ }^{1}$ Kelma Patrícia de Souza, ${ }^{1}$ Denise Regina da Costa Aguiar, ${ }^{1}$ Leonice Domingos dos Santos Cintra Lima

${ }^{1}$ Universidade Brasil

Correspondência

Kelma Patrícia de Souza

Universidade Brasil

Fernandópolis, SP - Brasil.

Email: kelma.biblio@gmail.com

ORCID: http://orcid.org/0000-0002-8112-9871

Submetido em: $15 / 06 / 2017$

Aceito em: 13/09/2017

Publicado em: 19/09/2017

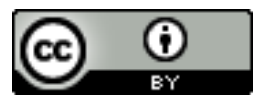

JITA: DC. Public libraries 
RESUMO: As bibliotecas são vitais para desenvolvimento social, cultural e ambiental das comunidades onde estão inseridas. Esta pesquisa objetivou: Investigar ações de sustentabilidade adotadas por uma biblioteca referência no país; Comparar as ações de sustentabilidade da biblioteca referência com as ações já desenvolvidas pela Biblioteca Central Santa Mônica (BCMON); Propor ações e projetos para a BCMON, que poderão proporcionar aos usuários e servidores da biblioteca um recinto de estudo e de trabalho participativo, inclusivo, acessível e ambientalmente engajado. A metodologia teve abordagem qualitativa, natureza exploratória, por meio de levantamento bibliográfico, pesquisa de campo (entrevista semiestruturada), análise de dados identificados em pesquisa bibliográfica, levantamento realizado nos sites das principais bibliotecas universitárias federais brasileiras, a respeito de ações sustentáveis e da ênfase aplicada à sustentabilidade. Podese constatar que a sustentabilidade social e econômica é sutilmente aplicada, por meio do acesso à informação, da inclusão social e digital e do retorno, aos investimentos recebidos, à sociedade na oferta de produtos e serviços. Porém, o cuidado com o meio ambiente e a prática da educação ambiental ainda são objetos de desatenção. $O$ produto final foi a construção de uma proposta inicial com algumas indicações para a promoção da sustentabilidade na BCMOM, que terá como ponto de partida o diálogo em busca da conscientização ambiental e da participação de toda equipe e comunidades de forma voluntária, democrática e autônoma.

PALAVRAS-ChAVE: Biblioteca universitária. Biblioteca pública. Educação em biblioteconomia.

ABSTRACT: Libraries are vital to the social, cultural, and environmental development of the communities where they are located. This paper aimed: to investigate sustainable actions adopted by a reference library in the country; to compare those sustainable actions with actions already developed in Biblioteca Central Santa Mônica - BCMON (Santa Mônica Central Library); to propose actions and projects for BCMON, which will possibly provide library users and staff with an all-embracing, participatory, accessible, and environmentallyminded work and study center. The methodology had a qualitative approach, of exploratory nature, by means of bibliographic gathering, by field research (semi-structured interview), by the analysis of the data identified in bibliographic research and by a survey conducted from the websites of the main Brazilian federal university libraries, regarding sustainable actions and the emphasis on sustainability. It is possible to verify that social and economic sustainability is subtly applied, through the access to information, through social and digital inclusion and the return of the investments received, to the society in the offer of products and services. However, the care for the environment and the practice of environmental education are still neglected. The final product was constructed by an initial proposal with some indications to promote sustainability in BCMOM, which will be based on the dialogue in search of environmental awareness and the participation of the whole staff and communities in a voluntary, democratic, and autonomous way.

KEYWORDS: Academic libraries. Public libraries. Information science education. Sustainable development.

RESUMEN: Las bibliotecas son vitales para el desarrollo social, cultural y ambiental de las comunidades en donde se encuentran. Esta investigación tuvo por objetivo investigar las acciones de sustentabilidad adoptadas por una biblioteca referencia en el país; comparar las acciones de sustentabilidad de la biblioteca referencia con las acciones ya desarrolladas por la Biblioteca Central Santa Mónica (BCMON); proponer acciones y proyectos a los usuarios y servidores de la biblioteca, un recinto de estudio y de trabajo participativo, incluyente, accesible y comprometido con el medio ambiente. La metodología tuvo un enfoque cualitativo, naturaleza exploratoria, por medio de levantamiento bibliográfico, investigación de campo (entrevista semiestructurada), análisis de datos identificados en investigación bibliográfica, levantamiento realizado en los sitios de las principales bibliotecas universitarias federales brasileñas, con respecto a las acciones sustentables y de énfasis aplicado a la sustentabilidad. Se puede constatar que la sustentabilidad social y económica es sutilmente aplicada, por medio del acceso a la información, de la inclusión social y digital y del retorno, a las inversiones recibidas, a la sociedad en la oferta de productos y servicios. Sin embargo, el cuidado con el medio ambiente y la práctica de la educación ambiental aún son objeto de desatención. El producto final fue la construcción de una propuesta inicial con algunas indicaciones para la promoción de la sustentabilidad en la BCMOM, que tendrá como punto de partida el diálogo en la búsqueda de la concientización ambiental y de la participación de todo el equipo y comunidades de forma voluntaria, democrática y autónoma.

PAlabRas Clave: Biblioteca pública. Biblioteca universitaria. Biblioteca estatal. Educación en biblioteconomía. 


\section{INTRODUÇÃ̃o}

Este trabalho deriva de pesquisa realizada para desenvolvimento de dissertação de mestrado profissional em Ciências Ambientais. O estudo abrangeu a análise de ações sustentáveis, de acordo com o tripé ambiental, social e econômico, adotadas pela Biblioteca Central Santa Mônica e a Biblioteca Parque Estadual do Rio de Janeiro/RJ, referência no país.

A Biblioteca Central Santa Mônica (BCMON), objeto de estudo desta pesquisa, está entre as oito ${ }^{1}$ bibliotecas do Sistema de Bibliotecas ${ }^{2}$ da Universidade Federal de Uberlândia (SISBI/UFU), criado em 1989. Como o próprio nome já a caracteriza, a BCMON é a biblioteca central que concentra toda a administração superior do SISBI/UFU, serviços de seleção, aquisição, catalogação e classificação de todo acervo das bibliotecas. Atualmente, em 2017, a biblioteca desenvolve algumas iniciativas direcionadas para a sustentabilidade social, econômica e ambiental, porém estas ações podem ser fortalecidas, ampliadas e divulgadas para possibilitar a conscientização e a participação efetiva de toda comunidade.

O objetivo da pesquisa foi investigar ações de sustentabilidade adotadas por uma biblioteca referência no Brasil e comparar com ações desenvolvidas pela Biblioteca Central Santa Mônica da Universidade Federal de Uberlândia. Como objetivo específico propor projetos e ações que poderão proporcionar aos usuários e servidores da BCMON um ambiente de estudo e de trabalho participativo, inclusivo, acessível e ambientalmente engajado.

As ações de sustentabilidade devem ser implantadas na BCMON perante o grande valor social e institucional que a mesma representa para a comunidade acadêmica e comunidade externa, de Uberlândia e região, considerando-se que as universidades e suas bibliotecas são instituições seculares, promotoras de cultura e formação humana.

\section{REFERENCIAL TEÓRICO}

A contextualização de desenvolvimento sustentável à luz das questões ambientais, não pode ser compreendido sem o seu tripé de fundamentação, que considera os aspectos do desenvolvimento econômico, desenvolvimento social e desenvolvimento ambiental.

O desenvolvimento sustentável, conceituado por Sachs (2004), deve envolver soluções sociais, econômicas e ambientalmente eficientes e agregadas, obedecer ao duplo imperativo ético da solidariedade com as gerações presente e futuras, exigindo a explicitação de critérios

\footnotetext{
${ }^{1}$ Cf. http://www.bibliotecas.ufu.br/node/835.

${ }^{2}$ O SISBI/UFU é composto por bibliotecas distribuídas em $11.675,70 \mathrm{~m}^{2}$. Possui um quadro de pessoal de 124 servidores/colaboradores e um acervo de livros de 328.834 exemplares, recebendo em 2015 um total de 1.113.060 usuários ${ }^{2}$, média de 6.434 usuários dia.
}

\begin{tabular}{l|l|l|} 
v.16 & n.1 & p. $119-145$
\end{tabular}

jan./abr. 2018 
de sustentabilidade social e ambiental e de viabilidade econômica.

Mas afinal o que é sustentável? Atualmente, a terminologia sustentável ganhou grandes contornos, pois a humanidade está demonstrando maior preocupação com as questões ambientais, a sociedade está refletindo sobre o impacto que o desenvolvimento a qualquer custo está provocando ao meio ambiente, as novas tendências em relação ao tema elencam que o desenvolvimento sustentável existirá somente se houver harmonia com o meio ambiente, a economia e o aspecto social.

O aspecto social do desenvolvimento é muito amplo, permite diferentes análises e identificação de várias situações, como cultura, lazer, moradia, saúde, entre outros. Sachs(2004) analisa que o emprego decente para todos, uma efetiva e justa distribuição primária de renda é a melhor forma de assegurar simultaneamente a sustentabilidade social e o crescimento econômico. A importância da educação é ressaltada por Sachs(2004) na medida em que contribui para a formação cultural, a conscientização, a compreensão dos direitos humanos, a possibilidade de participação e o desenvolvimento da autonomia.

Para a promoção de quaisquer empreendimentos visando o desenvolvimento sustentável é imprescindível o envolvimento do estado e da sociedade, bem como um planejamento estratégico que tenha uma visão global, que contemple o equilíbrio entre o tripé da sustentabilidade: sociedade, econômica e o meio ambiente. $\mathrm{O}$ desenvolvimento não sustentável é ambientalmente incorreto provocando a perda da biodiversidade, é economicamente inviável, ocorrerá a má distribuição de renda e é socialmente injusto ocasionando a exclusão social.

Bibliotecas são espaços para organização do conhecimento, guarda e criação de cultura, preservação histórica dos povos e nações. Bibliotecas são ambientes que recebem e prestam atendimento às demandas apresentadas in loco ou virtualmente, de forma democrática e imparcial.Diante de todo contexto representativo o qual as bibliotecas estão envolvidas podemos dizer que as mesmas são imprescindíveis para desenvolvimento social, cultural e ambiental das comunidades onde estão inseridas.

As bibliotecas, por característica, incentivam a sustentabilidade social por meio do estabelecimento de práticas de inclusão social e digital, às pessoas com deficiências e aos menos favorecidos economicamente, oferecendo de forma gratuita, orientada e acessível o acesso ao seu espaço físico, aos conteúdos informacionais, democratizando o acesso à informação a toda sociedade sem quaisquer restrições.

A responsabilidade social também está voltada para a dimensão ambiental. No dia 28 de outubro de 2010 a International Organization for Standardization (ISO) publicou a norma internacional ISO 26000 - Guidance on social responsability e em 1 de novembro do mesmo ano, a Associação Brasileira de Normas Técnicas (ABNT), único representante da ISO no 
território brasileiro, publicou a versão em português NBR ISO 26000 - Diretrizes sobre responsabilidade social que a define como o compromisso de uma organização pelos impactos de suas decisões e atividades na sociedade e no meio ambiente, por meio de um comportamento ético e transparente, que esta organização deve contribuir também para o Desenvolvimento Sustentável (DS), saúde e bem-estar da sociedade (ASSOCIAÇÃO BRASILEIRA DE NORMAS TÉCNICAS, 2010). A abrangência ambiental da responsabilidade social exige que as bibliotecas, enquanto organizações cumpram seu papel de promotoras do desenvolvimento social e ambiental.

Para aquisição e produção do conhecimento é salutar que o ambiente, dentro de seus vários aspectos, esteja adequado e seja convidativo, harmônico, seguro e confortável. Para a constituição destes ambientes é fundamental que os gestores e toda equipe das bibliotecas conheçam a comunidade, os usuários, estejam atentos aos avanços tecnológicos, às novidades na área da biblioteconomia e às demandas, bem como estarem atualizados de acordo com os acontecimentos que envolvem a população no seu cotidiano. A sustentabilidade é um dos temas de grande abordagem na sociedade contemporânea. Desta forma, o mesmo precisa ser tratado com a seriedade e relevância que merece, considerando que um ambiente sustentável promove o bem-estar social, aumenta a qualidade de vida, contribui para a preservação do meio ambiente e da vida humana.

A Red de Bibliotecas Universitarias (Espanha) (2012)(REBIUN) ${ }^{3}$ destaca a importância da participação das bibliotecas para promoção da responsabilidade social e a sustentabilidade universitária, enfatiza duas situações: em primeiro lugar, devem estabelecer parceria e conexão para áreas como a gestão de recursos humanos, gestão ambiental, programas sociais, entre outras e em segundo lugar, incorporar profissionais bibliotecários em seus aspectos específicos, como serviços de biblioteca, gestão de coleções, acesso aberto, entre outros, bem como estratégias e iniciativas relativas a responsabilidade e sustentabilidade para o desenvolvimento das universidades. A REBIUN reafirma a importância do papel que pensadores e gestores das bibliotecas e bibliotecários, devem assumir a responsabilidade e o compromisso de potencializar e modernizar as bibliotecas.

O tema sustentabilidade é consideravelmente complexo e abrangente, desta forma deve ser caracterizado de acordo com o contexto o qual está inserido. $\mathrm{O}$ foco principal desta pesquisa foi explorar a sustentabilidade em bibliotecas com o objetivo de investigar ações sustentáveis adotadas por uma biblioteca referência no Brasil e comparar com as ações aplicadas pela Biblioteca Central Santa Mônica, a principal biblioteca do Sistema de Bibliotecas da Universidade Federal de Uberlândia/MG.

Durante o processo de pesquisa nas páginas eletrônicas das sessenta e três bibliotecas universitárias federais brasileiras, identificadas na página eletrônica do Ministério da

${ }^{3} \mathrm{Cf}$. http://www.rebiun.org/Paginas/Inicio.aspx

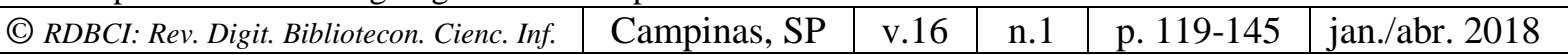


Educação (MEC) ${ }^{4}$, nos dias 27 a 30 de abril de 2016, consultamos a missão, a visão e demais conteúdo das páginas e não localizamos em nenhuma delas ações sustentáveis concretas, conforme quadro 1 .

Quadro 1 - Universidades Federais Brasileiras - Bibliotecas - Abordagem ambiental

\begin{tabular}{|c|c|}
\hline $\begin{array}{l}\text { Aborda questões } \\
\text { ambientais? }\end{array}$ & Universidade/Sistema de Bibliotecas \\
\hline Sim & $\begin{array}{l}\text { Universidade Federal do Amazonas, Universidade Federal do Oeste do Pará e } \\
\text { Universidade Federal de Uberlândia. }\end{array}$ \\
\hline Não & $\begin{array}{l}\text { Universidade de Brasília, Universidade Federal de Goiás, Universidade Federal de } \\
\text { Mato Grosso, Universidade Federal da Grande Dourados, Universidade Federal de } \\
\text { Mato Grosso do Sul, Universidade Federal do Acre, Universidade Federal do Amapá, } \\
\text { Universidade Federal do Pará, Universidade Federal Rural da Amazônia, Fundação } \\
\text { Universidade Federal de Rondônia, Universidade Federal de Roraima, Universidade } \\
\text { Federal do Tocantins, Universidade Federal de Alagoas, Universidade Federal do } \\
\text { Oeste da Bahia, Universidade Federal do Recôncavo da Bahia, Universidade Federal } \\
\text { da Bahia, Universidade Federal do Ceará, Universidade Federal do Cariri, } \\
\text { Universidade da Integração Internacional da Lusofonia Afro-Brasileira, Universidade } \\
\text { Federal do Maranhão, Universidade Federal da Paraíba, Universidade Federal do } \\
\text { Vale do São Francisco, Universidade Federal de Pernambuco, Universidade Federal } \\
\text { Rural de Pernambuco, Universidade Federal do Piauí, Universidade Federal do Rio } \\
\text { Grande do Norte, Universidade Federal do Sergipe, Universidade Federal do Espírito } \\
\text { Santo, Universidade Federal de Alfenas, Universidade Federal de Minas Gerais, } \\
\text { Universidade Federal dos Vales do Jequitinhonha e Mucuri, Universidade Federal de } \\
\text { Itajubá, Universidade Federal de Juiz de Fora, Universidade Federal de Lavras, } \\
\text { Universidade Federal de Ouro Preto, Universidade Federal de São João Del Rey, } \\
\text { Universidade Federal do Triângulo Mineiro, Universidade Federal de Viçosa, } \\
\text { Universidade Federal Fluminense, Universidade Federal do Estado do Rio de Janeiro } \\
\text {, Universidade Federal do Rio de Janeiro , Universidade Federal Rural do Rio de } \\
\text { Janeiro, Universidade Federal de São Carlos, Universidade Federal do ABC, } \\
\text { Universidade Federal de São Paulo, Universidade Federal do Paraná, Universidade } \\
\text { Tecnológica Federal do Paraná, Universidade Federal da Integração Latino- } \\
\text { Americana, Universidade Federal de Bagé, Universidade Federal de Pelotas, } \\
\text { Universidade Federal do Rio Grande do Sul, Universidade Federal do Rio Grande, } \\
\text { Universidade Federal de Santa Maria, Universidade Federal da Fronteira Sul e } \\
\text { Universidade Federal de Santa Catarina. }\end{array}$ \\
\hline Sem dados & $\begin{array}{l}\text { Universidade Federal do Sul e Sudoeste do Pará, Universidade Federal do Sul da } \\
\text { Bahia, Universidade Federal de Campina Grande, Universidade Federal Rural do } \\
\text { Semi-Árido e Universidade Federal de Ciências da Saúde de Porto Alegre. }\end{array}$ \\
\hline
\end{tabular}

Fonte: A autora (2016)

Pode-se observar algumas iniciativas, porém em apenas 4,8\% das bibliotecas pesquisadas,resultado aquém da nossa expectativa considerando a relevância do tema. $\mathrm{O}$ Sistema de Bibliotecas ${ }^{5}$ (SISTEBIB) da Universidade Federal do Amazonas (UFAM) apresenta na sua missão "Cultivar o saber em todas as áreas do conhecimento por meio do ensino, da pesquisa e da extensão, contribuindo para a formação de cidadãos e o desenvolvimento da Amazônia." (UNIVERSIDADE FEDERAL DO AMAZONAS. SISTEMA DE BIBLIOTECAS, 2016). A intenção de contribuir com o desenvolvimento da Amazônia, considerada por alguns como o "pulmão do mundo" pela produção de oxigênio e

${ }^{4}$ Cf. http://portal.mec.gov.br/A24 e http://emec.mec.gov.br/

${ }^{5} \mathrm{Cf}$. http://biblioteca.ufam.edu.br/

\begin{tabular}{|c|c|c|c|c|c|}
\hline (C) RDBCI: Rev. Digit. Bibliotecon. Cienc. Inf. & Campinas, SP & v.16 & n.1 & p. $119-145$ & jan./abr. 2018 \\
\hline
\end{tabular}


por servir de equilíbrio ambiental, em função da abundante cadeia ecológica, do ecossistema e dos recursos naturais, principalmente hídrico. Outra menção de promoção do desenvolvimento da Amazônia foi enunciada pelo Sistema Integrado de Bibliotecas da Universidade Federal do Oeste do Pará (SIBI/UFOPA), também na sua missão "Atender a comunidade acadêmica com qualidade, prestando serviço eficiente e eficaz de acesso à informação, visando à produção e a disseminação do conhecimento técnico-científico e cultural para o desenvolvimento da Amazônia." (UNIVERSIDADE FEDERAL DO OESTE DO PARÁ. SISTEMA DE BIBLIOTECAS, 2011).

O SISBI/UFUapresentou em sua visão ${ }^{6}$ "Ser referência regional, nacional e internacional de universidade pública na promoção do ensino, da pesquisa e da extensão em todos os campus, comprometida com a garantia dos direitos fundamentais e com o desenvolvimento regional integrado, social e ambientalmente sustentável." (UNIVERSIDADE FEDERAL DE UBERLÂNDIA, 2016), a intencionalidade de promover o desenvolvimento sustentável. Essa visão foi construída pela equipe do SISBI/UFU durante o desenvolvimento do Plano Institucional de Desenvolvimento e Expansão (PIDE) 2016-2020 da UFU. O PIDE deve constar as diretrizes, as metas, os programas e os planos de ação projetados em todas as áreas de atuação da universidade.

A ausência de iniciativas sustentáveis nas bibliotecas pesquisadas desperta a atenção para a relevância desta pesquisa no propósito de ser um motivador para que as bibliotecas e unidades de informação do país incluam em suas políticas de atuação, procedimentos em benefício da preservação e educação ambiental. Weber (2012) acrescenta que as bibliotecas precisam concretizar ações práticas de educação ambiental, que o ambiente esteja desenvolvido pelo homem e para o homem favorecendo a responsabilidade individual e coletiva.

Mediante a dificuldade de percepção de uma biblioteca universitária federal brasileira que fosse referência, o campo de busca foi ampliado para outros tipos de bibliotecas, porém sempre com foco central em uma biblioteca sustentável. Durante a investigação, em abril de 2016, constatamos que a primeira e única biblioteca brasileira a alcançar certificação ambiental era a Biblioteca Parque Estadual ${ }^{7}$ (BPE), do governo do Rio de Janeiro. A certificação foi concedida pelo Leadership in Energy and Environmental Design (LEED), Estados Unidos, categoria Gold, que trata-se de um sistema internacional de certificação na área de construção sustentável.

Outros sistemas que são referências neste tipo de certificação são o Building Research Establishment Environmental Assessment Method (BREEAM) ${ }^{8}$, lançado em 1990, na

\footnotetext{
${ }^{6} \mathrm{Cf}$. http://www.bibliotecas.ufu.br/institucional

${ }^{7} \mathrm{Cf}$. http://www.bibliotecasparque.rj.gov.br/

${ }^{8} \mathrm{Cf}$. http://www.breeam.com/

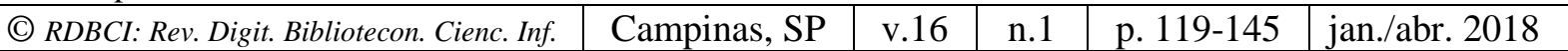


Inglaterra, o Haute Qualité Environnementale $(\mathrm{HQE})^{9}$, também apresentado no início dos anos 90, na França e o Green Star ${ }^{10}$, criado em 2003, pelo Green Building Council da Austrália.De acordo com o(BRASIL, 2009), devem ser observados 9 princípios que orientam as diretrizes de uma construção ambientalmente equilibrada, sendo: planejamento sustentável da obra, aproveitamento passivo dos recursos naturais, eficiência energética, gestão e economia de água, gestão dos resíduos na edificação, qualidade do ar e do ambiente interior, conforto termo-acústico, uso racional de materiais e uso de produtos e tecnologias ambientalmente amigáveis.Os princípios citados deveriam ser exigências em quaisquer construções.

A formação do cidadão não se restringe apenas à educação formal e aos docentes, todos aqueles que trabalham com atendimento ao público, com diferentes públicos, nos âmbitos formais e não formais, também devem compreender a importância do seu papel de formador, por meio de exemplos, do cuidado com o ambiente de trabalho e com a qualidade do atendimento.

A educação ambiental tornou-se obrigatória nos espaços públicos, com qual intencionalidade? A favor do quê e a favor dequem, se consolida uma proposta de educação ambiental em uma biblioteca e com qual paradigma?

Em uma perspectiva de humanização, de uma ética humana e ambiental, é que se desenvolve a presente pesquisa, como a possibilidade de construção de uma educação ambiental em uma biblioteca sustentável, fundamentada no pensamento e na obra de Paulo Freire. Para isso,dentre outras, foram abordadasasseguintes vertentes: conscientização, participação, autonomia, diálogo e escuta.

Paulo Freire observa a profundidade do significado da palavra conscientização, para ele a educação, como prática de liberdade, é um ato de conhecimento, uma aproximação crítica da realidade. (FREIRE, 1980).

A definição de conscientização, para Freire, se divide em duas situações a consciência ingênua e a consciência crítica, em relação à última Paulo Freire destaca que esta representa a evolução do pensamento humano por instigar a indagação:

Num primeiro momento a realidade não se dá aos homens como objeto cognoscível por sua consciência crítica. Noutros termos, na aproximação espontânea que o homem faz do mundo, a posição normal fundamental não é uma posição crítica, mas uma posição ingênua. A este nível espontâneo, o homem ao aproximar-se da realidade faz simplesmente a experiência da realidade na qual ele está e procura. Esta tomada de consciência não é ainda conscientização, porque esta consiste no desenvolvimento crítico da tomada de consciência. A conscientização implica, pois, que ultrapassemos a esfera espontânea de apreensão da realidade, para chegarmos a uma esfera crítica na qual a realidade se dá como objeto cognoscível e na qual o homem assume uma posição epistemológica. (FREIRE, 1980, p. 26).

\begin{tabular}{|c|c|c|c|c|c|}
\hline $\begin{array}{l}{ }^{9} \mathrm{Cf} . \text { http://www.behqe.com/ } \\
{ }^{10} \mathrm{Cf} . \text { http://new.gbca.org.au }\end{array}$ & & & & & \\
\hline (C) RDBCI: Rev. Digit. Bibliotecon. Cienc. Inf. & Campinas, SP & $\mathrm{v} .16$ & n.1 & p. $119-145$ & jan./abr. 2018 \\
\hline
\end{tabular}


Desta forma, a conscientização é um convite a pensarmos sobre a nossa existência, sobre as situações que nos circundam, uma reflexão acerca de nossos atos e ações. Freire sobre a conscientização observa que:

\begin{abstract}
A conscientização é neste sentido, um teste de realidade. Quanto mais conscientização, mas se "des-vela" a realidade, mais se penetra na essência fenomênica do objeto, frente ao qual nos encontramos para analisá-lo. Por essa mesma razão a conscientização não consiste em "estar frente a realidade" assumindo uma posição falsamente intelectual. A conscientização não pode existir fora da"práxis", ou melhor, sem o ato ação-reflexão. Esta unidade dialética constitui, de maneira permanente, o modo de ser ou de transformar o mundo que caracteriza os homens. (FREIRE, 1980, p. 26).
\end{abstract}

O sujeito que passou por um processo educacional que fomentou à crítica ao pensamento, é um sujeito que pode deixar de ser ingênuo e de ter um pensar distorcido do mundo. Neste processo quando o educando e o educador optam pela mudança, pelo pensar certo, atuam em sincronia, educador e educando se conscientizam (FREIRE, 1979).

No processo da educação ambiental pode-se observar o quanto é fundamental conscientização, a consciência crítica do homem em relação à atual situação do meio ambiente, a humanidade deve estar consciente da necessidade de mudança, da necessidade de compreender, estabelecer uma parceria entre natureza e desenvolvimento, a preservação ambiental deve ser tratada como prioridade.

A relevância da conscientização para o enfrentamento dos problemas ambientais foi destacada em 1987, quando a Comissão Mundial sobre Meio Ambiente e Desenvolvimento(CMMAD), publicou o Relatório Brundtland" ${ }^{11}$ laçou o slogan "Pensar globalmente, agir localmente", sugerindo que deveríamos pensar as questões ambientais mundiais, trazê-las para a nossa realidade, na nossa comunidade ou região.

A conscientização requer diálogo e escuta, pois possibilita o exercício da tolerância, de se colocar no lugar do outro em determinadas situações, de ter uma escuta atenta considerando o ponto de vista do outro e desta forma agir para mudar a realidade.

De acordo com Freire (1980, p. 28) "Quanto mais conscientizados nos tornamos, mais capacitados para ser anunciadores e denunciados, graças ao compromisso de transformação que assumimos". Freire ainda destaca a importância da participação efetiva, da necessidade da tomada de iniciativa e do cumprimento dos compromissos assumidos, onde ressalta que"esta posição deve ser permanente: a partir do momento em que denunciamos uma estrutura desumanizante sem nos comprometermos com a realidade, a partir do momento em que chegamos à construção do projeto, se deixarmos de ser utópicos nos burocratizamos" (FREIRE, 1980, p. 28). Somente o homem pode mudar a realidade é imprescindível conhecêla e mudá-la quando necessário.

${ }^{11} \mathrm{Cf}$. http://www.un-documents.net/ocf-02.htm\#I

\begin{tabular}{l|l|l|l|l|l}
\hline (C) RDBCI: Rev. Digit. Bibliotecon. Cienc. Inf. & Campinas, SP & v.16 & n.1 & p. 119-145 & jan./abr. 2018 \\
\hline
\end{tabular}


A conscientização gera a participação, a relevância do homem participativo que muda o ambiente em que vive. De acordo com Díaz Bordenave (1989, p. 22)“[...] a palavra participação vem da palavra parte. Participação é fazer parte, tomar parte ou ter parte [...]", é necessário observar a diferença dimensional nos termos fazer parte e tomar parte, este último demonstra realmente o envolvimento do indivíduo na situação a que lhe é apresentada, havendo comprometimento, fazer parte não requer uma ação efetiva de participação, possui um significado mais superficial, pois podemos fazer parte de algo sem ter voz ativa.

Paulo Freire afirma a importância da educação como forma de garantir a participação. Uma educação crítica e emancipatória possibilita aos sujeitos do processo a debater suas experiências, problemas, situações-limites do cotidiano, emergindo de uma posição de submissão, de espectador para a participação. (FREIRE, 1967).

A participação é uma ação social de convivência, conflito e consenso, pois garantir a atuação de todos é fundamental para constituição de uma sociedade democrática, mais justa e solidária.

Bordenave considera que o diálogo é também uma força para a participação,

\begin{abstract}
Ora, a maior força para a participação é o diálogo. Diálogo, aliás, não significa somente conversa. Significa se colocar no lugar do outro para compreender seu ponto de vista; respeitar a opinião alheia; aceitar a vitória da maioria; pôr em comum as experiências vividas, sejam boas ou ruins; partilhar a informação disponível; tolerar longas discussões para chegar a um consenso satisfatório para todos. (DÍAZ BORDENAVE, 1989, p. 50).
\end{abstract}

O diálogo é o ponto central destacado para a promoção da conscientização e da participação, onde se aplicados são capazes de provocar a melhoria da realidade. O diálogo também deverá ser considerado o ponto de partida para a implantação da educação ambiental e da sustentabilidade na Biblioteca Central Santa Mônica, a realidade somente poderá ser melhorada se for de fato conhecida e interpretada.

A participação é fundamental, principalmente quando se trata de pauta que apresenta situações do cotidiano, com interesse coletivo, defender interesses ou benefícios que atendam a um respectivo grupo social. Nessa tendência surge o meio ambiente e a educação ambiental, temas tratados em função dos recorrentes problemas ambientais e nas situações do cotidiano, onde vivenciamos a realidade do desenvolvimento não sustentável.

De acordo com Díaz Bordenave (1989, p. 17)“[...] Tudo indica que o homem só desenvolverá seu potencial pleno uma sociedade que permita e facilite a participação de todos. O futuro ideal do homem só se dará numa sociedade participativa”. A sociedade brasileira não possui um considerável hábito participativo, principalmente na constituição de políticas públicas ou quaisquer outras tomadas de decisão de impacto social. A ausência da participação decorre, principalmente pela falta de consciência social e política da população, 
é necessário entender que participando poderemos construir uma sociedade melhor, a participação provoca a mudança da sociedade.

A Participação possui relação direta com a última dimensão freireana aqui dissertada, a autonomia, o sujeito participante tem liberdade para se tornar parte de algo, possui independência para expressar seus argumentos e suas ações. A participação é condição para a autonomia.

É necessário formar sujeitos com autonomia para uma educação ambiental. Freire destaca que ser humano deve ser respeitado, ser ouvido e de posse de autonomia para participar no seu grupo social. Paulo Freire afirma que "o respeito à autonomia e à dignidade de cada um é um imperativo ético e não um favor que podemos ou não conceder uns aos outros." (FREIRE, 2005, p. 59).

O sujeito de posse de autonomia deve estar consciente do seu poder de modificar o ambiente em que vive, do quão importante é a liberdade de participar de mudanças que promovam principalmente o bem-estar de todos, bem como assumir as consequências da autonomia que deve ser utilizada com responsabilidade. Devidamente compreendidos, os princípios e conceitos freire anos, serão fundamentais para fundamentar o tripé do desenvolvimento sustentável: a sustentabilidade social, econômica e Ambiental.

\section{METODOLOGIA}

A metodologia utilizada nesta pesquisa teve uma abordagem qualitativa, com natureza exploratória, por meio de levantamento bibliográfico em livros, artigos, teses, entre outros, pesquisa de campo (entrevista semiestruturada) e análise de dados identificados em pesquisa bibliográfica referente à temática sustentabilidade ambiental e bibliotecas sustentáveis, publicadas em livros, artigos, teses e dissertações, entre outros e levantamento realizado nas páginas eletrônicas das principais bibliotecas universitárias federais brasileiras, a respeito de ações sustentáveis e da ênfase aplicada à sustentabilidade.

Nesta pesquisa também foi aplicado o método comparativo em que as informações coletadas foram confrontadas com a atual situação da Biblioteca Central Santa Mônica (BCMON) da Universidade Federal de Uberlândia. O produto final foi uma proposta inicial com algumas indicações de iniciativas para a promoção da sustentabilidade na Biblioteca Central Santa Mônica, que será entregue à administração do SISBI/UFU.

Para seleção da biblioteca referência em sustentabilidade foram analisadas a missão, a visão e demais conteúdo das páginas eletrônicas das sessenta e três bibliotecas universitárias federais brasileiras, essa pesquisa constatou que 4,8\% das bibliotecas pesquisadas apresentam algumas iniciativas. $\mathrm{Na}$ ausência de ações sustentáveis concretas, como objeto de estudo comparativo com a Biblioteca Central Santa Mônica da UFU,foi selecionada a Biblioteca

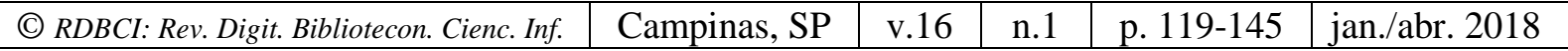


Parque Estadual (BPE), do governo do Rio de Janeiro. Optou-se pela BPE ${ }^{12}$, por se tratar de uma biblioteca acessível, envolvida em ações sociais e culturais, que contempla em uma de suas missões a educação ambiental, contribuindo para a formação de uma população consciente, preocupada com o ambiente ${ }^{13}$, iniciativa ainda pouco comum na realidade das bibliotecas brasileiras, e por ser a primeira e única biblioteca brasileira a alcançar a Certificação $L E E D$ categoria Gold. O LEED é um sistema internacional de certificação e orientação ambiental para edificações, utilizado em 143 países, e possui o intuito de incentivar a transformação dos projetos, obra e operação das edificações, sempre com foco na sustentabilidade de suas atuações ${ }^{14}$.

A pesquisa previa também a visita à $\mathrm{BPE}$, porém a mesma, juntamente com seus usuários e colaboradores, também foi vítima da violenta crise financeira instaurada no Estado do Rio de Janeiro o qual toda equipe foi cumpriu aviso até o mês de dezembro de 2016, desta forma foi realizada uma entrevista online com uma bibliotecária que fazia parte da equipe da BPE, concedendo a entrevista via web conferência, por meio do software Skype, no dia 23 de fevereiro de 2017, de 11h12 às 12h30.Durante a entrevista foram abordados temas como: criação da BPE, produtos e serviços oferecidos, gestão da biblioteca e abordagens no tripé sustentável, a sustentabilidade social, a econômica e a ambiental, bem como os pontos positivos e negativos do processo.

Por ocasião do fechamento da BPE não foi possível a realização da visita e consequentemente o registro fotográfico. Desta forma, as imagens apresentadas na pesquisa são oriundas da internet e dos arquivos do SISBI/UFU que conta com imagens efetuadas durante uma Visita Técnica realizada pelo bibliotecário do SISBI/UFU, Paulo de Assis Cunha, no dia 6 de outubro de 2015. Para análise dos dados foram confrontadas as informações coletadas no levantamento bibliográfico da literatura em questão, na pesquisa realizada nas páginas eletrônicas das bibliotecas e na entrevista.

\section{RESULTADOS}

Como resultado da pesquisa apresentamos a análise comparativa entre as ações sustentáveis adotadas pela BPE e pela BCMON, bem como uma proposta inicial de intervenção de sustentabilidade em bibliotecas que será entregue à administração do SISBI/UFU.

\footnotetext{
${ }^{12}$ Apesar de o SISBI/UFU fazer parte da esfera pública federal e a BPM, da estadual, entendemos que as ações de sustentabilidade independem das características das bibliotecas, bem como pela função de ambas bibliotecas que oferecer é oferecer à comunidade a qual está inserida um atendimento eficiente e com qualidade em prol do desenvolvimento social, cultural e ambiental.

${ }^{13} \mathrm{Cf}$. http://www.bibliotecasparque.rj.gov.br/sample-page-2/sustentabilidade/

${ }^{14} \mathrm{Cf}$. http://www.gbcbrasil.org.br/sobre-certificado.php

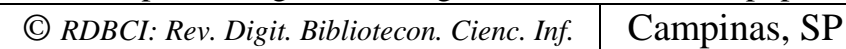

\begin{tabular}{l|l|l} 
v.16 & n. 1 \\
\hline
\end{tabular}

\begin{tabular}{l|l} 
p. $119-145$ & jan./abr. 2018
\end{tabular}
}




\subsection{Biblioteca Parque Estadual e suas ações sustentáveis}

As bibliotecas parque, cumpridoras do seu papel social, propõem ofertar às comunidades os quais estão inseridas o acesso à informação, à cultura, à convivência e à arte e segundo a entrevistada a BPE por meio dos seus projetos, produtos e serviços oferecidos à comunidade configuram uma maior ênfase para sustentabilidade social.

Dentre os moradores da comunidade ou do entorno devemos considerar e destacar as pessoas em situação de rua que se estabelecem na região. A entrevistada relatou o tratamento que essas pessoas recebem enquanto frequentadoras da BPE, bem como os projetos que promovem a inclusão social. Às pessoas em situação de rua que utilizavam a biblioteca é atribuída uma ficha social, essas pessoas não têm endereço, diante disso é informado o endereço do abrigo e as que não vivem em abrigos são encaminhadas a um mediador social. O mediador realiza uma entrevista e realiza um cadastro complementar ao disponível pelo software de gerenciamento das bibliotecas, no cadastro complementar é possível inserir mais informações como onde elas estavam, em que região viviam, entre outros, destacando que não é necessário ter comprovante de residência para fazer o cadastro na BPE.

A equipe da BPE começou a refletir sobre o que mais seria possível fazer e oferecer aos mesmos e assim surgiu o projeto Uma Só $\mathrm{Voz}^{15}$, que consistia em um coro que passou a se concentrar na BPE, o projeto era para todos interessados, porém a grande maioria dos participantes eram usuários em situação de rua. Posteriormente o projeto se desdobrou para aulas de teatro que atingiu esse mesmo público. Outro projeto de destaque foi um curso com formação em gastronomia, que foi uma parceria com a Calouste Gulbenkian.

Outro público de destaque que compõem o entorno da BPE são os estudantes das escolas públicas municipais, a entrevistada destacou que há um relacionamento bem intenso com as turmas da Escola Municipal Rivadavia Correa e da Escola Municipal Tiradentes, a BPE tornou-se quintal dessas escolas. A BPE aos sábados oferece ações especiais para o público infantil. A participação de estudantes das escolas municipais na BPE demonstra o quanto o projeto é relevante para a comunidade, significa que a biblioteca está atuando diretamente na formação destas crianças, na formação de leitores e futuros profissionais e principalmente cidadãos.

Quando consideramos a sustentabilidade social e a inclusão social não podemos ignorar as pessoas com deficiência. Para atender esta categoria de usuários, o acervo é constituído de audiolivros, livros digitais e livros em Braille, neste contexto a BPE está localizada em um edifício totalmente acessível, com rampa, elevador, piso e sinalização tátil, bem como cabines para deficientes visuais e ledores, adaptadas para cadeiras de rodas. A entrevistada exemplificou e confirmou que a biblioteca é fisicamente acessível, narrando a

${ }^{15} \mathrm{Cf}$.https://www.facebook.com/umasovoz.withonevoice/

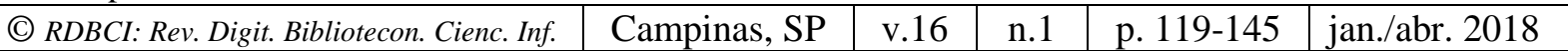


passagem da tocha paraolímpica pela BPE. Contudo há restrição de acesso no entorno, os funcionários da BPE acompanham os usuários com deficiência visual até o metrô e os entregam ao guarda do metrô.A formação continuada da equipe é um processo que deve ser previsto nas bibliotecas, principalmente a capacitação em acessibilidade, considerando que são várias as demandas para cada um dos diferentes tipos de deficiência.

As tecnologias assistivas, dispositivos, equipamentos, processos e técnicas, são necessárias para que as pessoas com deficiência tenham acesso à informação proporcionando um atendimento adequado e inclusivo. A entrevistada cita algumas tecnologias disponibilizadas pela BPE como o scanner Sarah CE que é utilizado por pessoas cegas ou com baixa visão, os bibliotecários do setor digitalizam o material e salvam em dispositivo para o usuário, Teclados especiais em Braille; Lente de aumento eletrônica para livros; Page turner, que vira as páginas para os leitores com deficiências físicas; Máquina fusora, que aquece ilustrações de carbono, gerando o efeito de alto-relevo e permitindo às crianças com deficiência visual "verem" os desenhos.

Para que o atendimento seja qualitativo a equipe deve estar devidamente formada e envolvida no propósito de atender ao cidadão, neste sentido a entrevistada descreveu um importante projeto de formação dos funcionários que foi possibilitado por meio de parceria privada. O projeto de acessibilidade da $\mathrm{PBE}^{16}$, patrocinado pela Cielo ${ }^{17}$, ofereceu o Curso de acessibilidade em bibliotecas e o Curso de introdução em Língua Brasileira de Sinais (Libras).O projeto de acessibilidade com a parceria da Cielo também proporcionou a aquisição do software Browsealoud ${ }^{18}$, que tem a função de ler o conteúdo da página eletrônica da biblioteca e até traduzir para outros idiomas.

O mantenedor da BPE é o Governo do Estado do Rio de Janeiro, que repassa aproximadamente $\mathrm{R} \$ 950.000,00$ (novecentos e cinquenta mil reais) por mês para o Instituto de Desenvolvimento e Gestão(IDG), Organização Social responsável pela gestão, manutenção e funcionamento da Rede Bibliotecas Parque. Para efeitos de análise da sustentabilidade econômica da BPE, nada melhor do que averiguar os números, desta forma consultamos o Relatório de Gestão Anual, do ano de $2015^{19}$, do IDG frente às Bibliotecas Parque, neste documento foram identificados os dados estatísticos da BPE, a entrevistada destacou que existem metas a serem cumpridas em relação à oferta de produtos e serviços, o que exigia uma grande dedicação e comprometimento da equipe. $\mathrm{O}$ acervo é composto por aproximadamente 175.000 itens e seu horário de funcionamento em 2015 foi de terça a sábado, de $11 \mathrm{~h}$ às $19 \mathrm{~h}$.

\footnotetext{
${ }^{16} \mathrm{Cf}$. http://www.reschdesign.com/bbp/estadual/a-biblioteca/acessibilidade/

${ }^{17} \mathrm{Cf}$. https://www.cielo.com.br/

${ }^{18} \mathrm{Cf}$. http://www.ibdd.org.br/acessibilidade.asp?t=

${ }^{19} \mathrm{Cf}$. http://www.idg.org.br/wp-content/uploads/2016/10/Relatorio-Gestao-anual-2015-Bibliotecas.pdf

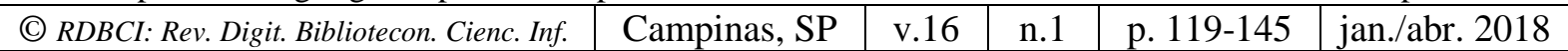


Das estatísticas consultadas no Relatório destacamos que a BPE recebeu 423.438 visitantes em 2015, sendo que foram efetuadas 202 visitas mediadas para escolas, destacando a participação do público infantil. Neste período foram cadastrados em 2015 22. 346 novos usuários.

Para elucidar ainda mais estes números e ampliar a compreensão do impacto que a sustentabilidade econômica da BPE produz identificamos os serviços informados no Relatório que são compatíveis com os serviços citados na calculadora de atribuição de valores aos produtos e serviços oferecidos por uma unidade de informacional, bem como a precificação sugerida por França, Autor X e Portela (2017), anexo A, após a identificação efetuamos a referida contabilidade, tabela 1, mesmo concordando com o posicionamento das autoras que consideram que atribuir e medir valor a cada um dos serviços informacionais oferecidos é uma das tarefas gerenciais mais desafiadoras e menos aplicadas nos ambientes informacionais.

Tabela 1 - Biblioteca Parque Estadual - Valoração - Ano base 2015

\begin{tabular}{|c|c|c|c|c|}
\hline Objetivos & Indicadores & Qtdade & $\begin{array}{l}\text { Valor } \\
\text { referência }\end{array}$ & Valor do Serviço \\
\hline \multirow{5}{*}{$\begin{array}{l}\text { Objetivos } \\
\text { de } \\
\text { atividades } \\
\text { fim }\end{array}$} & Empréstimos do acervo & 69.156 & $\mathrm{R} \$ 176,15$ & $\mathrm{R} \$ 12.181 .829,40$ \\
\hline & Visitantes (Frequência) & 423.438 & $\mathrm{R} \$ 35,00$ & $\mathrm{R} \$ 14.820 .330,00$ \\
\hline & $\begin{array}{l}\text { Alunos atendidos em visitas } \\
\text { guiadas }\end{array}$ & 5.491 & $R \$ 11,25$ & $\mathrm{R} \$ 61.773,75$ \\
\hline & $\begin{array}{l}\text { Escolas atendidas em visitas } \\
\text { guiadas }\end{array}$ & 202 & $\mathrm{R} \$ 11,25$ & $R \$ 2.272,50$ \\
\hline & $\begin{array}{l}\text { Acervo adquirido (sem } \\
\text { periódicos) }\end{array}$ & 165 & $\mathrm{R} \$ 176,15$ & $\mathrm{R} \$ 29.064,75$ \\
\hline \multirow{2}{*}{$\begin{array}{l}\text { Objetivos } \\
\text { de } \\
\text { cidadania }\end{array}$} & $\begin{array}{l}\text { Itens de acervo especial para } \\
\text { Pessoa com Deficiência }\end{array}$ & 760 & $\mathrm{R} \$ 176,15$ & $\mathrm{R} \$ 133.874,00$ \\
\hline & $\begin{array}{l}\text { Funcionários habilitados na } \\
\text { linguagem de sinais }\end{array}$ & 1 & $\mathrm{R} \$ 1.303,57$ & $\mathrm{R} \$ 1.303,57$ \\
\hline \multicolumn{4}{|c|}{ TOTAL } & $\mathrm{R} \$ 27.230 .447,97$ \\
\hline
\end{tabular}

Fonte: A autora (2017)

Para atribuir os valores de referência foi parametrizado por analogia entre os indicadores da BPE apresentados no relatório e o valor de referência dos serviços informacionais da BCMON apresentados no Anexo A. Em relação a empréstimos do acervo, mediante a ausência de detalhamento do tipo de material foi aplicado o valor de referência estabelecido para Livros; visitantes (frequência): foi atribuído valor de referência de Uso de salas de estudo em grupo, multimídia e videoconferência; alunos e escolas atendidas em

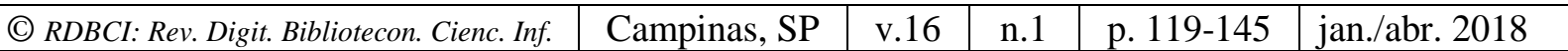


visitas guiadas: foi atribuído valor de referência para Capacitação - Visita orientada; acervo adquirido (sem periódicos): foi atribuído valor de referência estabelecido para Livros e Funcionários habilitados na linguagem de sinais: foi atribuído valor de referência de Participação em eventos, reuniões.

O valor total dos 7 indicadores da BPE foi de $\mathrm{R} \$ 27.230 .447,97$ (vinte e sete milhões, duzentos e trinta mil, quatrocentos e quarenta e sete reais e noventa e sete centavos), um valor representativo considerando que é efetuado um investimento anual de $\mathrm{R} \$ 11.400 .000,00$ (onze milhões e quatrocentos mil reais) para manutenção da BPE, também devemos considerar que vários outros indicadores não foram contemplados na planilha. A maioria de indicadores que não foram citados são inerentes à Objetivos de gestão, Atividades culturais e Atividades educativas.

O problema de falta de reconhecimento e de investimento financeiro em instituições educacionais e culturais é um problema peculiar do Brasil, principalmente pelas instituições que são mantidas pelo poder público. Os números acima citados confirmam que BPE colabora com a sustentabilidade econômica, na qual o valor investido é retornado na forma da prestação de serviços à comunidade, na inclusão social e na formação de cidadãos leitores.

A principal particularidade da BPE é a ênfase na sustentabilidade onde essa preocupação pode ser comprovada pelo fato de projeto ser desenvolvido com o propósito da preocupação com o meio ambiente, esta inciativa colheu frutos pois a construção recebeu a certificação ambiental pelo $L E E D$ categoria Gold, primeira e única biblioteca no Brasil a receber o título. O LEED é um sistema internacional de certificação e orientação ambiental para edificações, utilizado em 143 países, e possui o intuito de incentivar a transformação dos projetos, obra e operação das edificações, sempre com foco na sustentabilidade de suas atuações. O Selo atesta a sustentabilidade da construção e assegura que todo processo foi realizado a qualidade dos sistemas implantados, como a redução dos resíduos e da poluição, do consumo de água e de energia, bem como a utilização de materiais regionais e a qualidade ambiental interna. $\mathrm{O}$ projeto de construção eficiente atribuiu ao prédio as seguintes características sustentáveis:

a) madeira certificada: todo piso é revestido de madeira certificada Forest Stewardship Council (FSC) ${ }^{20}$, que assegura o manejo responsável das florestas;

b) conforto térmico: para ampliar o conforto térmico foram utilizados:

- $\quad$ toda a estrutura foi pintada de branco;

- $\quad$ vidros duplos de proteção solar, com alto fator de sombra, reduzem em até $52 \%$ a entrada de calor e também minimizam o barulho;

- $\quad$ substituição dos cobogós por chapas de aço cortén perfuradas;

${ }^{20}$ O Conselho de Manejo Florestal (tradução nossa) é uma organização independente, não governamental, sem fins lucrativos, criada para promover o manejo florestal responsável ao redor do mundo. Cf. https://br.fsc.org/ptbr

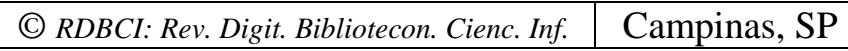

\begin{tabular}{l|l|l|l} 
v.16 & n.1 & p. $119-145$
\end{tabular}

jan./abr. 2018 
- telhado verde que abrange aproximadamente $2.000 \mathrm{~m}^{2}$, atenuando a temperatura interior, evitando a formação de ilhas de calor;

c) utilização de energia solar para produção de energia elétrica: o teto inclinado da claraboia recebeu em toda extensão placas fotovoltaicas para produção de $20 \%$ da energia consumida, cerca de 50 mil megawatts por ano. O projeto foi viabilizado pela Light Serviços de Eletricidade S. A., por meio do programa estadual Rio Capital da Energia. O custo total do equipamento é de $\mathrm{R} \$ 585 \mathrm{mil}$;

d) aproveitamento da iluminação natural: o edifício possui luz natural abundante, com a luz controlada pela claraboia e pelas frestas entre os elementos portantes, destinada a suprir a área da biblioteca. De acordo com a entrevistada a iluminação natural atendia muito bem, considerando ainda que o Rio tem muita luz, a iluminação só não atende totalmente no inverno, neste período, por volta das $17 \mathrm{~h}$, é necessário acender as lâmpadas. No restante do período a iluminação natural supria toda demanda;

e) reaproveitamento de água pluvial: a água das chuvas são aproveitadas para uso na irrigação de jardins e serviços gerais, proporcionado uma economia de aproximadamente $45 \%$ de água;

f) economia de água: implantação de torneiras com controle automático de tempo e vazão de água;

g) ar condicionado balanceado: o sistema foi balanceado com os demais dispositivos de controle térmico para evitar desperdícios, e conta também com uma central de água gelada com tanque de reserva, somente utilizado nos momentos de pique de energia.

Todas as iniciativas e ações sustentáveis são divulgadas aos frequentadores, com objetivo de divulgação e conscientização, sendo que esta é um dos processos da educação ambiental.

A entrevistada destacou que um dos pontos negativos do mobiliário sustentável era a manutenção, o mobiliário é coberto por uma película que sai com muita facilidade e a partir do momento que se solta a mesma tem que ser trocada por inteiro.

Todos os resultados apresentados demonstram a importância das bibliotecas para o contexto da construção de uma sociedade cidadã, participativa e consciente. Neste papel de formação devem ser incluídas as ações de sustentabilidade social, econômica e ambiental para inclusão do desenvolvimento sustentável como premissa de uma sociedade que pensa no futuro de suas gerações. Para o desenvolvimento das bibliotecas e a eficiência de suas atividades é imprescindível que as mesmas sejam reconhecidas como mecanismos transformadores e assim que sejam feitos os investimentos necessários tanto pela iniciativa pública como privada. 


\subsection{Biblioteca Central Santa Mônica e suas ações sustentáveis}

A BCMON é uma biblioteca universitária, inaugurada em 1991 para constituir o SISBI/UFU, atualmente, 2017, possui a condição de a principal biblioteca do sistema, pois é a maior em dimensão,aproximadamente $8.000 \mathrm{~m}^{2}$, em 2015 recebeu uma frequência média de 3.610 usuários por dia, a mesma também possui maior número de acervo e em dados estatísticos de acesso e utilização de seus produtos e serviços ${ }^{21}$, além de centralizar a administração o SISBI/UFU. A BCMON adota todas as ações sustentáveis, ao ser realizada uma análise do tripé sustentabilidade social, econômica e ambiental.

Pode-se dizer que a sustentabilidade social a BCMON oferece aos seus usuários atendimentos de inclusão social, mediante a percepção da necessidade de atender o público que não tem condições de adquirir equipamentos próprios e até mesmo pagar pelo acesso à internet para efetuar suas pesquisas a BCMON oferece produtos e serviços como acesso à recursos informacionais e ambientes de estudo, empréstimo domiciliar de dispositivos móveis, tais como: netbook, tablets e e-readers, ilhas de pesquisa, internet sem fio, pontos de rede e de energia e scanner planetário para digitalização de documentos sem custos, bem como a disponibilização de algumas tecnologias assistivas para acesso à informação para as pessoas com deficiência, como: Dosvox, DSpeech, Lupa eletrônica, Monitvox, NonVisual Desktop Access (NVDA), Winamp.

Talvez por se tratar de um edifício inaugurado em 1991, a estrutura física possui algumas barreiras arquitetônicas, não sendo favorável à acessibilidade. $\mathrm{O}$ acesso aos pavimentos superiores por pessoas com deficiência é possibilitado apenas por meio de um elevador que na impossibilidade de uso do mesmo a circulação é prejudicada, pois a biblioteca não possui rampas. Outro dificultador de circulação é a ausência de sinalização tátil e visual. Observamos também outras iniciativas necessárias como a formação de servidores para o atendimento às pessoas com deficiência, a disponibilização dos recursos de acesso à informação em maior quantidade e os softwares instalados em todos os computadores, bem como a disponibilização de um local específico para melhor acolher e ampliar a possibilidade de novos serviços.

$\mathrm{Na}$ vertente da sustentabilidade econômica, o investimento financeiro aplicado à biblioteca é compensado mediante a concessão de produtos e serviços à comunidade interna e externa, desta maneira identificamos as características da sustentabilidade econômica exercida pela BCMON para elucidar, apresentamos uma tabela proposta por França,Autor X,e Portela (2017) para calcular a valoração dos serviços informacionais oferecidos pela BCMON, referente ao ano base 2015, Anexo A. A calculadora foi adaptada à ferramenta desenvolvida pela Rede de Bibliotecas do Conselho Superior de Investigações Científicas da

${ }^{21} \mathrm{Cf}$. http://www.antigo.bibliotecas.ufu.br/

\begin{tabular}{l|l|l|l|l|l}
\hline (C) RDBCI: Rev. Digit. Bibliotecon. Cienc. Inf. & Campinas, SP & v.16 & n.1 & p. 119-145 & jan./abr. 2018 \\
\hline
\end{tabular}


Espanha (CSIC), criada em 2012. Os valores ultrapassaram R $\$ 30.000 .000,00$ (trinta milhões de reais), valor aproximadamente 30 vezes maior do que o valor investido anualmente.

Desde 2011, algumas ações de sustentabilidade ambiental foram efetivadas, estas ações objetivaram a promoção e a conscientização em relação à educação ambiental, o consumo sustentável entre os servidores e usuários, a humanização nas atividades de trabalho e a oferta de produtos e serviços com qualidade e eficiência. O quadro 2 apresenta de forma sucinta as ações adotadas e seus respectivos objetivos diretos.

Quadro 2 - Biblioteca Central Santa Mônica - Ações sustentáveis e objetivos

\begin{tabular}{|c|c|c|}
\hline$\overline{\mathbf{A C ̧ A ̃ O}}$ & ANO & OBJETIVOS \\
\hline Implantação do SIGAMI ${ }^{22}$. & 2011 & $\begin{array}{l}\text { Redução do consumo de papel em formato A4 e } \\
\text { de tinta para impressão. }\end{array}$ \\
\hline $\begin{array}{l}\text { Publicação da resolução } \mathrm{n}^{\circ} 05 / 2011^{23} \\
\text { do CONDIR que disciplina as } \\
\text { condições e as rotinas de recebimento } \\
\text { e de desfazimento de material } \\
\text { informacional no âmbito das } \\
\text { Bibliotecas da UFU. }\end{array}$ & 2011 & $\begin{array}{l}\text { Recebimento: evita o recebimento de material } \\
\text { indesejado, minimizando o acúmulo de resíduos. } \\
\text { Desfazimento: contribui economicamente com } \\
\text { outras instituições por meio da disponibilização } \\
\text { de doações e também evita o acúmulo de } \\
\text { resíduos. }\end{array}$ \\
\hline $\begin{array}{l}\text { Recolhimento de lâmpadas } \\
\text { fluorescentes. }\end{array}$ & 2012 & Descarte correto de lâmpadas inservíveis. \\
\hline Distribuição de canecas. & 2013 & $\begin{array}{l}\text { Redução do consumo e da despesa com } \\
\text { aquisição de copos descartáveis. }\end{array}$ \\
\hline $\begin{array}{l}\text { Envio de recibos de empréstimo por e- } \\
\text { mail. }\end{array}$ & 2013 & $\begin{array}{l}\text { Redução do consumo de papel e do gasto na } \\
\text { aquisição de bobinas. }\end{array}$ \\
\hline $\begin{array}{l}\text { Disponibilização de scanners para } \\
\text { reprografia e envio das imagens por e- } \\
\text { mail ou em } U S B \text {. }\end{array}$ & 2013 & $\begin{array}{l}\text { Redução do consumo de papel, economia } \\
\text { financeira para o usuário e preservação do } \\
\text { material informacional. }\end{array}$ \\
\hline $\begin{array}{l}\text { Disponibilização de papel para } \\
\text { rascunho. }\end{array}$ & 2013 & $\begin{array}{l}\text { Destinação correta para o resíduo, preservação } \\
\text { do mobiliário, diminuição do consumo de } \\
\text { material e do tempo gasto na limpeza. }\end{array}$ \\
\hline Campanha Asas doSilêncio. & 2013 & Diminuição de ruído. \\
\hline Coletores de pilhas e baterias. & 2014 & Descarte correto de pilhas e baterias. \\
\hline
\end{tabular}

Fonte: A autora (2016).

\footnotetext{
${ }^{22}$ Sistema de Gerenciamento e Aquisição de Material Informacional. Cf. http://www.sigami.ufu.br/

${ }^{23} \mathrm{Cf}$. http://www.bibliotecas.ufu.br/sites/bibliotecas.ufu.br/files/media/documento/resolucao_n05_2011_ rotinas_recebimento_desfazimento_de_matinformacional.pdf 
Em função da ausência de registros de informações não foi possível apresentar dados estatísticos específicos da BCMON que ilustram o impacto na diminuição dos gastos com material de consumo, o quantitativo de resíduos que não foram descartados de maneira incorreta, entre outros, porém abaixo contextualizamos todo o processo referente às ações, possibilitando evidenciar a percepção destes impactos.

O SIGAMI foi desenvolvido pelo Sistema de Bibliotecas em parceria com o Centro de Tecnologia da Informação da UFU (CTI/UFU), o mesmo foi desenvolvido para modernizar as atividades de aquisição que,entre 1996 a 2010,foram gerenciadas pelos 4 sistemas a seguir:

a) Solicitação Online: sistema onde era efetuado o registro das solicitações. As chefias do Setor de Seleção e Aquisição (SESEL) e do Setor de Periódicos acessavam os pedidos, os imprimia e os distribuía aos servidores que analisavam manualmente cada pedido;

b) Base Aquisição: após a análise das solicitações, as mesmas eram digitadas, uma a uma, na Base Aquisição;

c) Pericon ${ }^{24}$ : sistema onde eram digitadas as solicitações de aquisição de periódicos, após a conclusão da análise; e

d) Baixa e Transferência: sistema utilizado para gerenciar a baixa e a transferência de todo material informacional das bibliotecas da UFU.

Os 4 sistemas não eram integrados e por estarem obsoletos não atendiam às atuais demandas, considerando a necessidade de agilizar e dar transparência aos processos, melhorar a comunicação com os solicitantes e principalmente devido ao aumento expressivo da quantidade de aquisições. Este fator tornava o processo trabalhoso, oneroso, inacessível e ambientalmente inadequado, considerando principalmente a imensa quantidade de papel e tinta utilizada para imprimir todas as solicitações.

A aquisição de material informacional pode ocorrer de 3 maneiras: compra, doações ou permuta. O SESEL efetua o recebimento de doações de material e estas doações chegam de maneira desordenada e na grande maioria das vezes inadequadas ao acervo, gerando um enorme acúmulo de resíduos. Diante da problemática a direção do SISBI/UFU em parceria com a Comissão Permanente de Análise Documental (COPAD), aprova a Resolução $\mathrm{n}^{\circ}$ 05/2011 do Conselho Diretor (CONDIR), que disciplina as condições e as rotinas de recebimento e desfazimento de material informacional no âmbito das bibliotecas da UFU. Esta resolução é considerada uma importante ação de sustentabilidade, pois evita o recebimento de material informacional indesejado, o acúmulo de resíduos, bem como, por meio do desfazimento, possibilita a outras instituições, devidamente credenciadas, o recebimento de obras provocando a redução de gastos, com aquisição.

\begin{tabular}{|c|c|c|c|c|c|}
\hline (C) RDBCI: Rev. Digit. Bibliotecon. Cienc. Inf. & Campinas, SP & v.16 & n. 1 & p. $119-145$ & jan./abr. 2018 \\
\hline
\end{tabular}


Em 2012, por meio da parceria com a Diretoria de Sustentabilidade Ambiental (DIRSU) da UFU, iniciou-se o recolhimento das lâmpadas inservíveis, as mesmas eram recolhidas e descartadas de maneira adequada e ambientalmente correta. Até 2012, na UFU, não havia logística reversa das lâmpadas fluorescentes. O impacto ambiental destas lâmpadas se dá em função do mercúrio alojado nas mesmas. De acordo com Bacila, Fischer e Kolicheski

\begin{abstract}
A reciclagem das lâmpadas que apresentam mercúrio é o processo mais eficaz para a minimização dos impactos ambientais, pois estas são $99 \%$ recicláveis após o uso. Para que essa reciclagem possa acontecer em grande escala e para que sejam seguidas as legislações federais publicadas em 2010 no Brasil, deve-se utilizar do sistema de logística reversa, visando recapturar o valor dos materiais e oferecer um destino ecologicamente correto.(BACILA; FISCHE; KOLICHESKI, 2014, p. 32)
\end{abstract}

Em 2013 podemos considerar que foi o ano com a maior incidência de ações sustentáveis, 5 no total, sendo estas:

a) distribuição de canecas, a primeira entrega dos utensílios em material acrílico, aos servidores ocorreu na oportunidade da confraternização do SISBI/UFU, em dezembro de 2013, posteriormente, foi enviado e-mail solicitando que utilizassem a caneca durante o horário de trabalho, com o objetivo da redução do consumo de copos descartáveis. Os copos descartáveis são produzidos a partir de matéria prima não sustentável, o polipropileno e também o poliestireno, subprodutos do petróleo, que podem levar de 200 a 450 anos para se decompor na natureza ${ }^{25}$;

b) envio dos recibos dos empréstimos efetuados pelos usuários por e-mail, possibilitado por meio da implantação do equipamento de autoempréstimo de material informacional. Destaca-se a importância da participação das TICs como meio na promoção da sustentabilidade. Neste caso, pode proporcionar maior comodidade aos usuários, redução do consumo de papel e do gasto na aquisição de bobinas;

c) disponibilização de scanners planetários, ocorreu no final do ano de 2013, possibilitou aos usuários a digitalização de partes de obras, de acordo com a lei de direitos autorais, com opções de envio por e-mail ou gravação em dispositivo USB. A iniciativa proporcionou economia financeira ao usuário, liberação de espaço físico e principalmente a diminuição do impacto ambiental por meio da redução de cópias em papel;

d) disponibilização de papel para rascunho para os usuários da BCMON é um produto do projeto de Preservação de obras e mobiliários das bibliotecas UFU: subprojeto disponibilização de rascunho ${ }^{26}$. A iniciativa promoveu uma melhor utilização dos mobiliários pelos usuários, a redução do gasto com produtos e do

\footnotetext{
${ }^{25}$ Cf. http://www.deltasaneamento.com.br/noticia/8/tabela-de-decomposicao-de-residuos-nanatureza\#.WLibX_nyvIU

${ }^{26}$ Projeto desenvolvido no SISBI/UFU: PORTELA, P. O.; RODRIGUES, A. P. O. (Coord.) Preservação de obras e mobiliários das bibliotecas UFU: subprojeto disponibilização de rascunho. Uberlândia, 2013.
}

\begin{tabular}{|c|c|c|c|c|}
\hline (C) RDBCI: Rev. Digit. Bibliotecon. Cienc. Inf. & Campinas, SP & v.16 & n. 1 & jan./abr. 2018 \\
\hline
\end{tabular}


tempo despendido na limpeza, economia no gasto com papel pelos usuários e pela instituição, pois o papel utilizado pelas unidades administrativas da UFU é aproveitado como rascunho, provocando também a diminuição da geração de resíduos e a destinação correta do papel reutilizado às cooperativas de reciclagem contratadas, atualmente, 2017, a Associações de Catadores e Recicladores de Uberlândia e Cooperativa dos Recicladores de Uberlândia; e

e) campanha "Asas do Silêncio", um projeto que a princípio foi desenvolvido com o objetivo de minimizar o ruído gerado pelos usuários no recinto da biblioteca. A Secretaria de Saúde e Segurança no Trabalho(BRASIL, 1994) classifica os ruídos como um dos riscos ambientais. A(ASSOCIAÇÃO BRASILEIRA DE NORMAS TÉCNICAS, 1987)estipula o nível de ruído para bibliotecas na faixa de 35 a 45 $\mathrm{dB}$.

As iniciativas citadas estão bastante aquém das possibilidades e das necessidades de tornar a BCMON um ambiente de convívio sustentável, com o oferecimento de produtos e serviços que evitem o impacto ambiental no presente e no futuro. Embora conscientes do seu compromisso social, cultural, econômico e ambiental, nem todas as bibliotecas estão preparadas para assumir tal responsabilidade. O conhecimento das melhores práticas e ações em prol da sustentabilidade são relevantes instrumentos de apoio para os servidores.

\subsection{Proposta de intervenção de sustentabilidade para a BCMON}

Após a realização da pesquisa, apresentaremos à gestão do SISBI/UFU uma proposta inicial com algumas indicações de iniciativas para a promoção da sustentabilidade na Biblioteca Central Santa Mônica. As sugestões iniciais serão dialogadas com a equipe do SISBI/UFU e parceiros institucionais e poderão ser ajustadas, excluídas ou ampliadas:

a) divulgar na página eletrônica do SISBI/UFU as ações sustentáveis já realizadas pelo SISBI/UFU;

b) criar o Programa de Sustentabilidade SISBI/UFU e instituir uma Comissão Programa de Sustentabilidade SISBI/UFU com objetivo de implantar a responsabilidade socioambiental na BCMON e realizar a gestão ambiental, com ações que envolvam:

- formar dos servidores em uma perspectiva conscientizadora;

- divulgar o programa e as ações sustentáveis estabelecidas;

- dialogar e incentivar a participação da comunidade interna e externa acolhendo sugestões de melhoria do programa;

- organizar eventos e

- executar e estabelecer parcerias e políticas, promovendo a participação de todos os interessados em contribuir com o projeto;

c) implantar a política dos 5R's, que deve priorizar a redução do consumo e o reaproveitamento de materiais: 
- Repensar: despertar a consciência ambiental no ser humano e repensar os hábitos de consumo;

- Reduzir: diminuir a quantidade de lixo produzido, consumir apenas o necessário, priorizar os produtos com maior durabilidade;

- Reaproveitar: utilizar novamente, dar nova utilidade aos materiais;

- Reciclar: transformar materiais considerados inservíveis em novos produtos, reduzindo resíduos, e

- Recusar consumir produtos que gerem impactos socioambientais significativos: utilizar apenas produtos certificados ambientalmente e que não agridem o meio ambiente, não recicláveis.

Estas condutas reduzem os gastos no tratamento do lixo, a extração de recursos naturais, a quantidade de resíduos nos aterros, o uso de energia elétrica nas indústrias e prestigia as cooperativas de catadores, recicladores, entre outros;

d) implantar a Agenda Ambiental na Administração Pública (A3P) ${ }^{27}$, a $\mathrm{A} 3 \mathrm{P}$ tem como objetivo de incorporar o programa de sustentabilidade na Administração Pública, por meio da implantação de princípios da responsabilidade socioambiental, estimulando mudanças de rotinas na administração pública, como mudança nos investimentos, compras e contratações de serviços pelo governo, sensibilização e capacitação dos servidores gestão adequada de recursos naturais utilizados e resíduos gerados e a promoção da melhoria da qualidade de vida no ambiente de trabalho. Os passos para implantação envolvem: criar e regulamentar a Comissão Gestora da A3P; Realizar diagnóstico ambiental; Desenvolver projetos e atividades; Mobilização e sensibilização; Avaliação e monitoramento(BRASIL, 2009);

e) obter certificação ambiental para construções das novas bibliotecas: é sabido que é necessário a construção de novas prédios para abrigar algumas bibliotecas da UFU, atualmente, 2017, as únicas bibliotecas que estão em prédios definitivos são a Biblioteca Central Santa Mônica e a Setorial Umuarama. Desta forma, há demanda de construção de pelo menos 6 edificações. Como sugestão também apontamos a contratação de profissionais com expertise neste tipo de construção e se necessário uma empresa de consultoria na área;

f) implantar novas ações e ampliar as existentes: desenvolver parcerias com demais órgãos da instituição para o desenvolvimento de projetos de implantação de ações sustentáveis, incluindo substituição de mobiliários e equipamentos e adequação da estrutura física, elétrica e hidráulica;

g) mensurar o impacto das ações sustentáveis: efetuar o gerenciamento do impacto das ações sustentáveis adotadas pelo SISBI/UFU, por biblioteca, para profunda análise e tomada de decisão;

h) promover e garantir a formação continuada da equipe;

${ }^{27} \mathrm{Cf}$. http://www.conab.gov.br/OlalaCMS/uploads/arquivos/10_12_22_16_43_26_cartilha_a3p..pdf

\begin{tabular}{l|l|l|l|l|l}
\hline (C) RDBCI: Rev. Digit. Bibliotecon. Cienc. Inf. & Campinas, SP & v.16 & n.1 & p. 119-145 & jan./abr. 2018 \\
\hline
\end{tabular}


i) construir Kits com os usuários que contemple material que contribua com a conscientização ambiental. Os kits podem incluir: copos ou squeezes para serem utilizados em substituição aos copos descartáveis, folders informativos sobre o projeto e a importância da preservação ambiental e como reciclar o lixo e economizar água e energia, entre outros;

j) criar bazar solidário, o qual voluntários podem doar materiais e equipamentos a serem repassados aos alunos em vulnerabilidade social e/ou econômica devidamente indicados pela Divisão de Assistência ao Estudante (DIASE) da UFU.

Com a implantação das sugestões espera-se que a BCMON e as demais bibliotecas da UFU sejam ambientalmente engajadas, ofereçam retorno à comunidade perante os investimentos financeiros recebidos, bem como sejam promotoras da inclusão social e digital.

\section{CONSIDERAÇÕES FINAIS}

Bibliotecas são ambientes que promovem a preservação histórica e cultural de uma comunidade local ou global, oferecem acesso à informação in loco ou à distância, participam da formação de profissionais e cidadãos e desta maneira colaboram diretamente para desenvolvimento social, cultural e ambiental das comunidades onde estão inseridas, proporcionando assim a sustentabilidade.

Este trabalho investigou as práticas sustentáveis de uma biblioteca referência em sustentabilidade no país e confrontou com as ações sustentáveis adotadas na Biblioteca Central Santa Mônica da Universidade Federal de Uberlândia.

No desenrolar da pesquisa foi possível verificar que a grande maioria das bibliotecas universitárias federais brasileiras não abordam diretamente o desenvolvimento sustentável em suas atividades, a sustentabilidade social e econômica é sutilmente aplicada, por meio do acesso à informação, da inclusão social e digital e do retorno, aos investimentos recebidos, à sociedade por intermédio da oferta gratuita de produtos e serviços. Porém, a sustentabilidade ambiental não recebe a devida importância que o tema merece, o cuidado com o meio ambiente e a prática da educação ambiental ainda são objetos de desatenção.

O produto final desta pesquisa será a entrega à administração do SISBI/UFU de uma proposta inicial com algumas indicações de sugestões de iniciativas para a promoção da sustentabilidade na Biblioteca Central Santa Mônica, que terá como ponto de partida o diálogo em busca pela conscientização ambiental, por meio da participação de toda equipe e comunidades interna e externa de forma voluntária, democrática e autônoma. 


\section{REFERÊNCIAS}

ASSOCIAÇÃO BRASILEIRA DE NORMAS TÉCNICAS. NBR 10152: níveis de ruído para conforto acústico. Rio de Janeiro: ABNT, 1987.

ASSOCIAÇÃO BRASILEIRA DE NORMAS TÉCNICAS. NBR ISO 26000: diretrizes sobre responsabilidade social $=$ guidance on social responsibility. Rio de Janeiro:

ABNT,2010.

BACILA, D. M.; FISCHE, K.; KOLICHESKI, M. B. Estudo sobre reciclagem de lâmpadas fluorescentes. Engenharia Sanitária e Ambiental, n. esp., p. 21-30, 2014.

BRASIL, Ministério do Meio Ambiente.Agenda Ambiental na Administração Pública. Brasília: MMA, 2009. Disponível em: <

http://www.mma.gov.br/images/arquivo/80063/cartilha\%20completa\%20A3P_.pdf $>$. Acesso em: 21 jul. 2016

BRASIL. Ministério do Trabalho e Emprego. Portaria n ${ }^{\circ} 25$, de dezembro de 1994. Aprova o texto da Norma Regulamentadora ${ }^{\circ}$ 9: riscos ambientais. Brasília: MTE, 1994.

DÍAZ BORDENAVE, J. E. O que é participação. 6. ed. São Paulo: Brasiliense, 1989.

FRANÇA, M. N.; SOUZA, K. P.; PORTELA, P. O. Quanto vale a informação? Calculando o valor econômico dos serviços de uma biblioteca. Revista Digital de Biblioteconomia e

Ciência da Informação, v. 15, n. 1, p. 265-281, jan. 2017.

FREIRE, P. Educação como prática da liberdade. Rio de Janeiro: Paz e Terra, 1967.

FREIRE, P. Educação e mudança. 12. ed. Rio de Janeiro: Paz e Terra, 1979.

FREIRE, P. Conscientização: teoria e prática da libertação: uma introdução ao pensamento de Paulo Freire. São Paulo: Cortez \& Moraes, 1980.

FREIRE, P. Pedagogia da autonomia: saberes necessários à prática educativa. 31. ed. São Paulo: Paz e Terra, 2005.

RED DE BIBLIOTECAS UNIVERSITARIAS (ESPANHA). Contribución de las bibliotecas en materia de responsabilidad social y sostenibilidad universitarias. In: CONFERENCIA DE RECTORES DE LAS UNIVERSIDADES ESPAÑOLAS. 2012. Madrid. Anais...Madrid, 2012. Disponível em: <

http://www.rebiun.org/documentos/Documents/IIIPE_2020_LINEA1/Contribucion_bibliotec as\%20universitarias_responsabilidad_social_y_sostenibilidad_REBIUN.pdf $>$. Acesso em:

21 jul. 2016

SACHS, I. Desenvolvimento includente, sustentável, sustentado. Rio de Janeiro:

Garamond, 2004.

UNIVERSIDADE FEDERAL DE UBERLÂNDIA. SISTEMA DE BIBLITECAS. Sistema de Bibliotecas: visão. Disponível em: < http://www.bibliotecas.ufu.br/institucional >. Acesso em: 27 abr. 2016.

UNIVERSIDADE FEDERAL DO AMAZONAS. SISTEMA DE BIBLIOTECAS. Sistema de Bibliotecas da Universidade Federal do Amazonas: missão e visão. Disponível em: < http://biblioteca.ufam.edu.br/sobre-sistebib/missao >. Acesso em: 28 abr. 2016. UNIVERSIDADE FEDERAL DO OESTE DO PARÁ. SISTEMA DE BIBLIOTECAS. Sistema de Bibliotecas: nossa missão. Disponível em: < 
http://www.ufopa.edu.br/institucional/suplementares/sistema-de-biblioteca-daufopa/biblioteca >. Acesso em: 28 abr. 2016.

WEBER, C. As bibliotecas e o aporte para o desenvolvimento sustentável. Responsabilidade e Reciprocidade, v. 1, n. 1, p. 491-496, 2012.

\section{ANEXO A - Valoração dos serviços informacionais da BCMON SISBI/UFU}

\begin{tabular}{|c|c|c|c|c|}
\hline \multicolumn{2}{|r|}{ Serviço } & Quantidade & Valor Referêncin & Vabr do Serviço \\
\hline \multirow{7}{*}{ Empréstimo } & Livros & 60.685 & $\mathrm{R} \$ 176,15$ & $\mathrm{R} \$ 10.689 .662,75$ \\
\hline & DVD & 796 & $\mathrm{R} \$ 90,33$ & $\mathrm{R} \$ 71.902,68$ \\
\hline & $\mathrm{CD}$ & 31 & $\mathrm{R} \$ 99,87$ & $\mathrm{R} \$ 3.095,97$ \\
\hline & Partituras & 339 & $\mathrm{R} \$ 65,82$ & $\mathrm{R} \$ 22.312,98$ \\
\hline & $\begin{array}{l}\text { Empréstimo Inte rbib lio tec as } \\
\text { UFU (EIB) }\end{array}$ & 627 & $R \$ 176,15$ & $\mathrm{R} \$ 110.446,05$ \\
\hline & $\begin{array}{l}\text { Empréstimo Entre Bibliotecas } \\
\text { (EEB) }\end{array}$ & 39 & $\mathrm{R} \$ 176,15$ & $\mathrm{R} \$ 6.869,85$ \\
\hline & Dispositivos móveis & 1.439 & $\mathrm{R} \$ 762,94$ & $\mathrm{R} \$ 1.097 .870,66$ \\
\hline \multirow{3}{*}{ Consulta } & Livros & 69.075 & $\mathrm{R} \$ 176,15$ & $\mathrm{R} \$ 12.167 .561,25$ \\
\hline & Revistas & 0 & $\mathrm{R} \$ 0,00$ & $\mathrm{R} \$ 0,00$ \\
\hline & Jomais & 0 & $\mathrm{R} \$ 0,00$ & $\mathrm{R} \$ 0,00$ \\
\hline \multicolumn{2}{|l|}{ Re prografia } & 73.205 & $\mathrm{R} \$ 0,10$ & $\mathrm{R} \$ 7.320,50$ \\
\hline \multicolumn{2}{|c|}{ Comutação bibliográfica } & 33 & $\mathrm{R} \$ 6,60$ & $\mathrm{R} \$ 217,80$ \\
\hline \multirow{2}{*}{ Acesso } & Audio books & 47 & $\mathrm{R} \$ 2,18$ & $\mathrm{R} \$ 102,46$ \\
\hline & Música & 7.629 & $\mathrm{R} \$ 3,49$ & $\mathrm{R} \$ 26.625,21$ \\
\hline \multirow{4}{*}{ Downioad } & E-books & 12.949 & $\mathrm{R} \$ 101,81$ & $\mathrm{R} \$ 1.318 .337,69$ \\
\hline & $\begin{array}{l}\text { Doc umentos - Bases de } \\
\text { Dados assinadas }\end{array}$ & 27.582 & $\mathrm{R} \$ 6,60$ & $\mathrm{R} \$ 182.041,20$ \\
\hline & $\begin{array}{l}\text { Artigos - Portal de Periódicos } \\
\text { Capes/MEC }\end{array}$ & 384.983 & $\mathrm{R} \$ 6,60$ & $\mathrm{R} \$ 2.540 .887,80$ \\
\hline & $\begin{array}{l}\text { Biblioteca Digital de Teses e } \\
\text { Dissertaçóes }\end{array}$ & 0 & $\mathrm{R} \$ 39,60$ & $R \$ 0,00$ \\
\hline \multicolumn{2}{|c|}{$\begin{array}{l}\text { Uso de salas de estudo em grupo, multimídia e } \\
\text { de videoconfe rência }\end{array}$} & 12.542 & $\mathrm{R} \$ 35,00$ & $\mathrm{R} \$ 438.970,00$ \\
\hline \multirow{3}{*}{ Capacitação } & Visita orientada & 1.255 & $\mathrm{R} \$ 11,25$ & $\mathrm{R} \$ 14.118,75$ \\
\hline & Bases de dados & 1.709 & $\mathrm{R} \$ 10,00$ & $\mathrm{R} \$ 17.090,00$ \\
\hline & Normalização & 260 & $\mathrm{R} \$ 8,33$ & $\mathrm{R} \$ 2.165,80$ \\
\hline \multirow[b]{2}{*}{ Formação } & Bibliote cários e assistentes & 0 & $\mathrm{R} \$ 0,00$ & $\mathrm{R} \$ 0,00$ \\
\hline & $\begin{array}{l}\text { Participação em eventos, } \\
\text { re uniões }\end{array}$ & 13 & $\mathrm{R} \$ 1.303,57$ & $\mathrm{R} \$ 16.946,41$ \\
\hline \multicolumn{2}{|c|}{$\begin{array}{l}\text { Uso de computadores para pesquisa } \\
\text { ac adê mica }\end{array}$} & 50.204 & $\mathrm{R} \$ 3,00$ & $\mathrm{R} \$ 150.612,00$ \\
\hline \multicolumn{2}{|c|}{ Serviços de Referência } & 54.877 & $\mathrm{R} \$ 22,92$ & $\mathrm{R} \$ 1.257 .780,84$ \\
\hline \multicolumn{2}{|c|}{ Catalogação na publicação } & 636 & $\mathrm{R} \$ 132,00$ & $\mathrm{R} \$ 83.952,00$ \\
\hline \multicolumn{2}{|c|}{ Informações por meio da página eletrônica } & 163 & $\mathrm{R} \$ 22,92$ & $\mathrm{R} \$ 3.735,96$ \\
\hline \multicolumn{4}{|c|}{ TOTAL } & $30.230 .626,61$ \\
\hline
\end{tabular}

Fonte: (FRANÇA; AUTOR X; PORTELA, 2017, p. 277) 

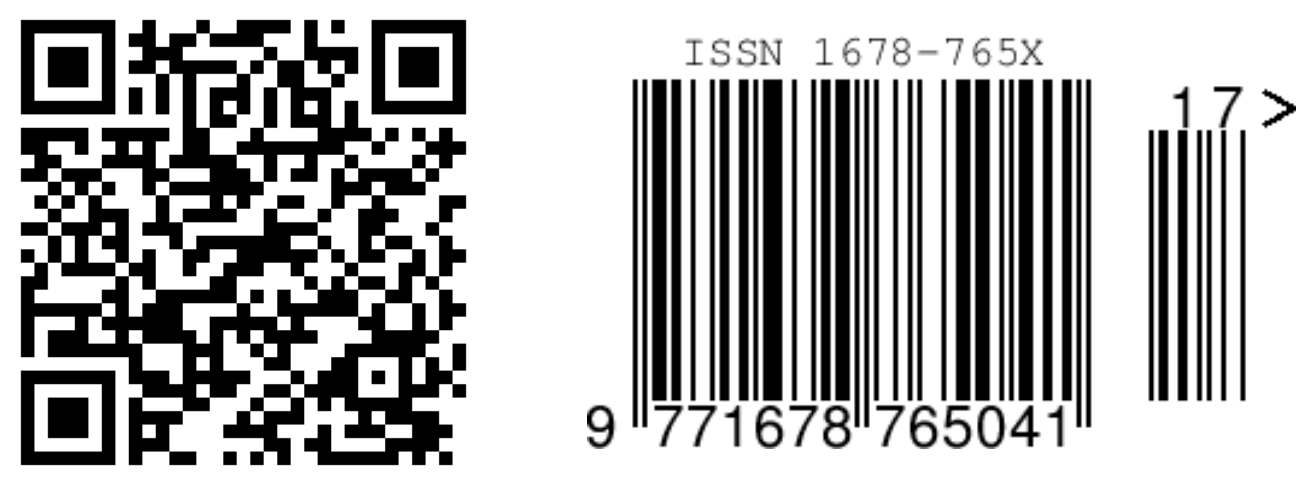